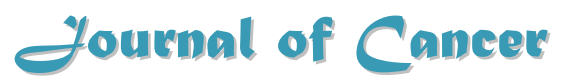

$2011 ; 2: 20-25$

Case Report

(C) Ivyspring International Publisher. All rights reserved

\title{
Complications of Methylene Blue Dye in Breast Surgery: Case Reports and Review of the Literature
}

\author{
FJ Reyes ${ }^{1}$, MB Noelck ${ }^{2}$, C Valentino ${ }^{3}$, L Grasso-LeBeau ${ }^{3}$, JE Lang ${ }^{1 凶}$ \\ 1. Department of General Surgery, Division of Surgical Oncology, University of Arizona, Tucson, AZ 85724, USA \\ 2. University of Arizona College of Medicine University of Arizona, Tucson, AZ 85724, USA \\ 3. University of Arizona Department of Pathology, Tucson, AZ 85724, USA
}

Corresponding author: Julie E. Lang, MD, Fax: 520-694-1820; Email: jlang@azcc.arizona.edu

Received: 2010.08.10; Accepted: 2010.12.05; Published: 2010.12.08

\begin{abstract}
Introduction: Methylene blue dye has been used worldwide successfully with few complications in breast surgery. We present two different complications involving methylene blue: I) skin and parenchymal necrosis when dye was injected in a subdermal fashion and 2) Mycoplasma infection caused by contaminated methylene blue in breast reduction surgery.

Methods: We present two cases seen at the University of Arizona during 2008 and referred to a breast surgeon for management. We evaluated and managed complications of methylene blue dye injected by 2 referring surgeons for different indications. A review of the literature was performed.

Results: The first case is a 67 year old female diagnosed with infiltrating ductal carcinoma of the left breast for which she was treated by her initial surgeon with left segmental mastectomy and sentinel node biopsy. The operating surgeon injected methylene blue in a subareolar subdermal fashion (distant from the primary tumor); unfortunately the patient suffered skin and breast necrosis requiring multiple surgical debridements and finally achieving delayed primary closure. The second case is a 45 year old female with infiltrating lobular carcinoma with a history of Mycoplasma infection secondary to methylene blue injected for breast reduction surgery. She required multiple debridements and had granulomas masquerading as cancer on MRI that confounded her extent of disease.

Conclusions: The use of methylene blue dye in breast surgery is not without risk. In both cases methylene blue was responsible for complications requiring surgical debridement for local wound problems. In each case severe necrosis and infection were present. Methylene blue may cause not only significant morbidity, but may also produce cosmetically unsatisfactory results.
\end{abstract}

Key words: Methylene blue, blue dye, complications, breast, surgery, adverse reactions, sentinel node

\section{Introduction}

Methylene blue dye (MBD) has been successfully used worldwide with few complications in patients undergoing breast surgery. We herein describe 2 different complications in 2 patients: 1) skin and parenchymal necrosis when MBD was injected subdermally and 2) Mycoplasma infection caused by contaminated MBD in breast reduction surgery.

Several publications advocate the use of subdermal MBD injections for SLN mapping without complications (1-3); however, several publications report complications ranging from blue staining of the skin and fat necrosis (4-6).

The American Society of Clinical Oncology (ASCO) guidelines advocate the use of blue dye in 
conjunction with radioisotope for SLN mapping as this combined strategy yields the highest rates of successful SLN mapping (7). Some surgeons prefer MBD over Lymphazurin (isosulphan blue dye) because Lymphazurin is more expensive, sometimes unavailable due to national shortages, and may rarely cause anaphylaxis $(3,8)$. Our objective is to bring to light the fact that although MBD is relatively safe, it is not without potential for serious complications.

\section{Methods}

The 2 patients described in these case reports were seen at the University of Arizona Cancer Center during 2008 and referred to a breast surgical oncologist for further care. We evaluated and managed complications of MBD injected by 2 referring surgeons for different indications.

\section{Case Report \# I}

A 67-year-old woman with a T1b N0 M0 infiltrating ductal carcinoma of the left breast was treated by a surgeon at the referring institution: she underwent a left segmental mastectomy and sentinel lymph node (SLN) biopsy for a $10 \mathrm{~mm}$ primary tumor located at the 9 o'clock position. The initial operating surgeon injected MBD in a subareolar subdermal fashion, complicated by MBD skin necrosis.

The patient initially presented describing pain and tenderness of her left breast that persisted for two months following her first surgery. We observed volume loss of the left breast and nipple retraction. We noted a sinus in the 8 o'clock position, draining purulent fluid; erythema surrounding the areola, extending toward the axilla; and fluctuance in the central breast. On breast ultrasound examination, an area of loculated fluid was detected and drained percutaneously. Culture results of this fluid showed Corynebacteria and anaerobic gram negative rods, which was clinically believed to be due to infection of the chronic open wound secondary to MBD necrosis. The patient was started on an oral antibiotic regimen without improvement.

We subsequently admitted the patient to the hospital to perform an incision and drainage (I\&D) of her left breast unresolving abscess cavity. We made an incision in the area of maximal fluctuance in the left breast in the periareolar region at 5 o'clock. To explore the borders of the cavity, we used a lacrimal probe; we noted that the cavity was connected to the sinus in the 8 o'clock position. The cavity measured approximately $8 \mathrm{~cm} \times 7 \mathrm{~cm} \times 2.5 \mathrm{~cm}$ and contained necrotic tissue. Then, we made a separate incision over the sinus in the 8 o'clock position and completely excised the tract. Once we debrided the cavity, we placed a wound vacuum-assisted closure (VAC) device for negative pressure treatment with suction drainage $(9,10)$ through 2 separate incisions (Figures $1-4)$.

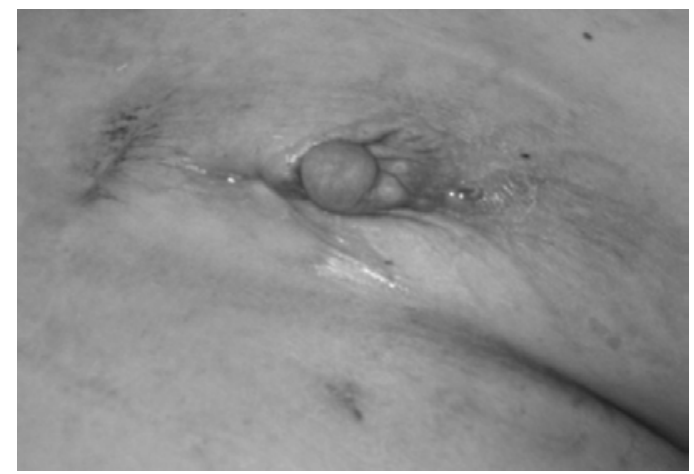

Figure I: The left breast exhibits nipple retraction, erythema, and purulent drainage prior to incision and drainage.

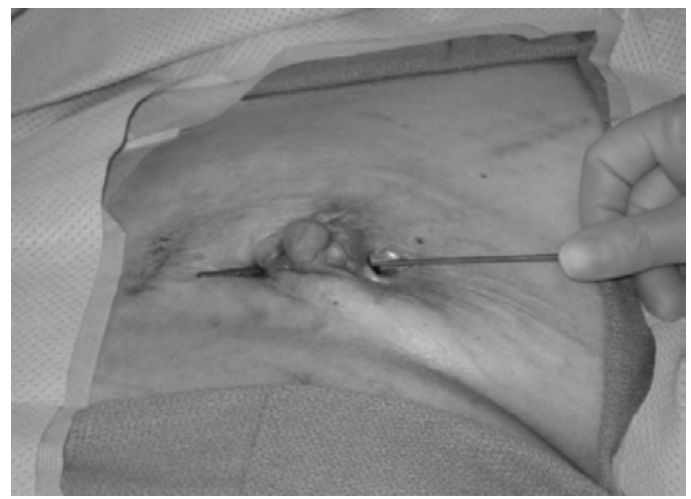

Figure 2: The probe demonstrates the connection between 2 draining chronic sinus tracts. In the original operation, methylene blue dye was injected in a subareolar fashion.

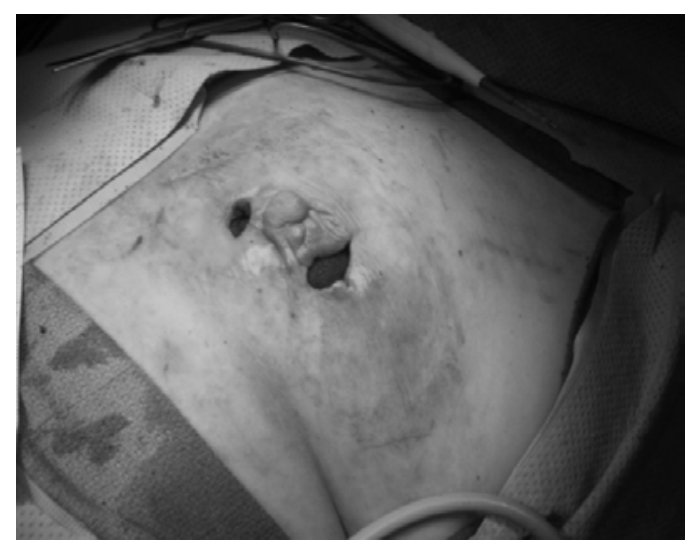

Figure 3: After debridement of the chronic breast abscess, a single wound vacuum-assisted closure (VAC) sponge was placed in the cavity; 2 VAC pads were used to apply negative pressure therapy through the 2 separate incisions. 


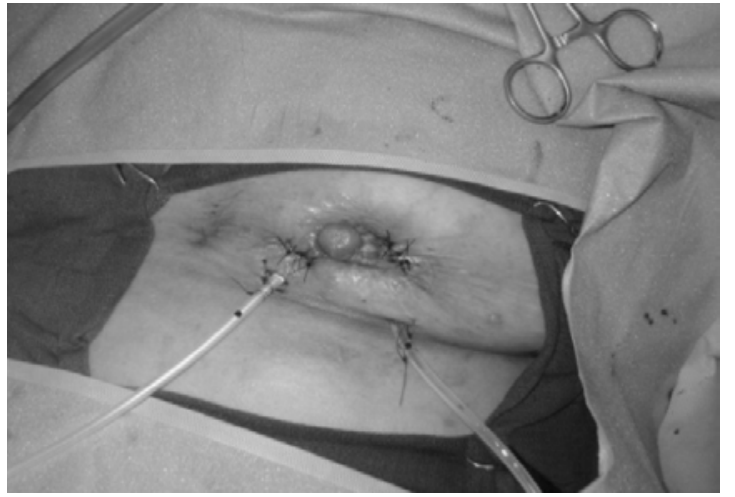

Figure 4: The breast is shown after wound VAC sponge removal and delayed primary closure over drains. Note the volume loss secondary to the MBD skin and breast necrosis.

\section{Case Report \#2}

A 45-year-old pre-menopausal woman underwent bilateral breast reductions performed by the referring surgeon in 2007. Her surgery was complicated by Mycoplasma chelonae infection secondary to contaminated MBD. She required multiple debridements, which resulted in extensive scar tissue and granuloma formation. The U.S. Centers for Disease Control and Prevention (CDC) have reported contamination of MBD with Mycobacteria chelonae in facelift patients in 2003(11). However, to our knowledge, infectious contamination of MBD has not been previously reported in any breast surgery patients. The patient's plastic surgeon that had previously performed her breast reductions cultured Mycobacteria chelonae directly from a contaminated bottle of MBD (personal correspondence, microbiology reports). This plastic surgeon had a series of 24 Mycoplasma chelonae infections secondary to MBD on several of his cosmetic surgery patients during a period of 3 months in 2007 (personal correspondence, microbiology reports). This was never reported to the CDC or elsewhere in the medical literature to date.

Our patient's follow-up mammogram showed distortion of the right breast in the upper quadrant, which was thought to be scarring from prior surgery, along with a separate mass, located in the 8 o'clock position, reported with the dimensions of $1.2 \mathrm{~cm}$. We performed an ultrasound-guided core biopsy of that mass and identified Nottingham grade 2 infiltrating lobular carcinoma with associated lobular carcinoma in situ.

A bilateral breast magnetic resonance imaging (MRI) showed a broad region $(6.2 \times 2.7 \mathrm{~cm})$ of abnormal enhancement in the right breast, which was suspicious for lobular carcinoma (Figures 6-7). To evaluate the extent of disease, we performed 3
MRI-guided core biopsies: 2 were negative for malignancy, and 1 revealed lobular carcinoma in situ. Thus, MRI was proven to overestimate her extent of disease secondary to her breast infections due to breast reduction.

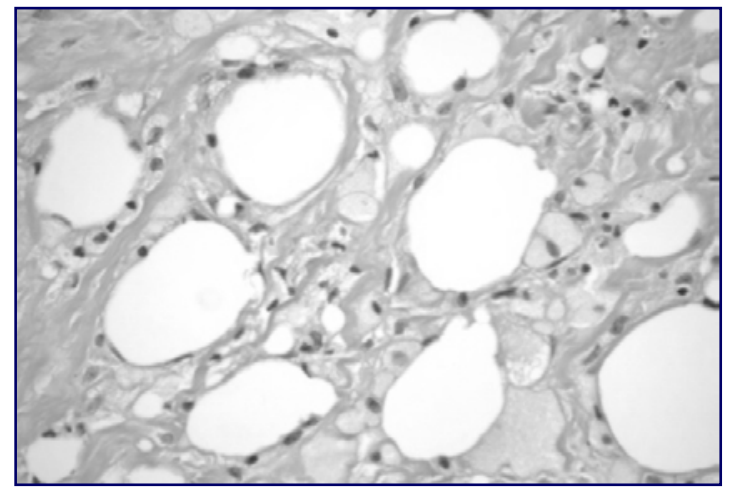

Figure 5: This photomicrograph shows tissue from the breast cavity. Note the foamy macrophages digesting dead adipocytes, indicating fat necrosis. The spaces between fat globules are filled by fibrosis.

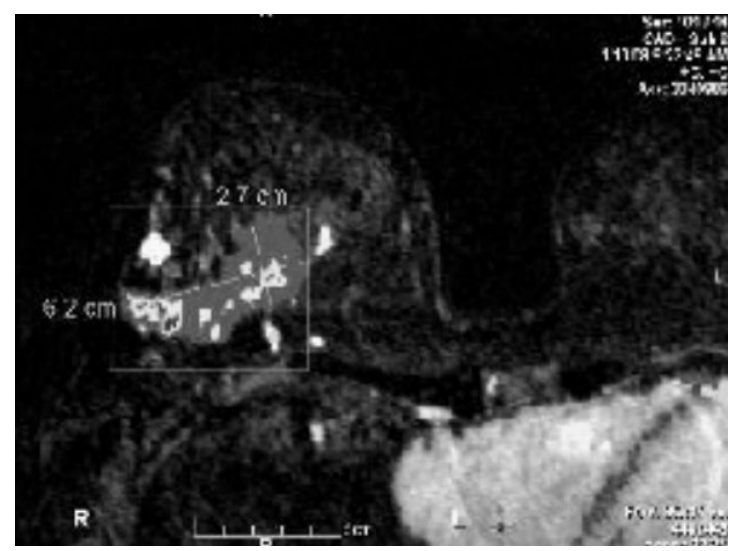

Figure 6: Note the measurements of the right breast mass per magnetic resonance imaging (MRI).

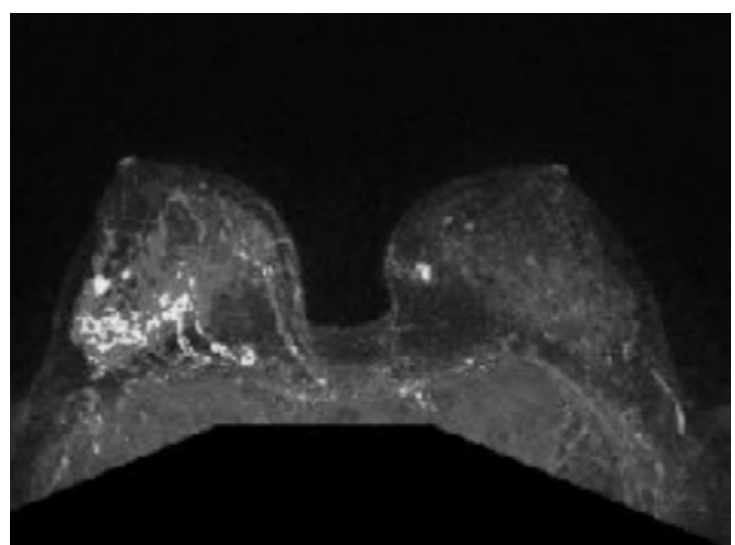

Figure 7: Bilateral breast MRI with gadolinium depicts the prominent right breast mass which overestimated the extent of disease. MRI measured the mass at $6.2 \times 2.7 \mathrm{~cm}$. Pathology measured the tumor at $1.8 \mathrm{~cm}$. 
The patient elected to undergo bilateral total skin-sparing mastectomies and right axillary SLN dissection. Final pathology of the right breast revealed a $1.8-\mathrm{cm}$, multifocal, grade 2 , invasive lobular carcinoma with associated lobular carcinoma in situ. Margins were $2 \mathrm{~cm}$ from the tumor, with none of the 4 SLNs involved. Her Oncotype DX recurrence score was 19 (intermediate risk). She enrolled in the Trial Assigning Individualized Options for Treatment (Tailor RX) and was randomized to undergo chemotherapy. Her chronic lingering infection was an important factor in the decision to use systemic therapy with cyclophosphamide, methotrexate, and 5-fluorouracil (CMF), to avoid neutropenia. Her history of bilateral breast infections requiring numerous debridements also factored into her decision making to select bilateral mastectomies. She has completed chemotherapy, underwent breast reconstruction and is maintained on tamoxifen hormonal therapy. She eventually successfully completed implant based breast reconstruction.

\section{Discussion}

\section{Surgical Considerations}

We are aware of only a few published complications of MBD in breast surgery patients (Table 1).

Table I. Known Complications of Methylene Blue Dye in Breast Surgery

\begin{tabular}{|c|c|c|c|}
\hline Study & $\begin{array}{l}\text { Surgical Proce- } \\
\text { dure }\end{array}$ & Complications & $\begin{array}{l}\text { Cases } \\
\text { (n) }\end{array}$ \\
\hline \multirow[t]{4}{*}{ Zakaria S et al (4) } & $\begin{array}{l}\text { Lymphatic map- } \\
\text { ping in breast } \\
\text { cancer }\end{array}$ & $\begin{array}{l}\text { Local inflamma- } \\
\text { tion }\end{array}$ & 21 \\
\hline & & Skin necrosis & 5 \\
\hline & & Blue staining & 5 \\
\hline & & Wheal and flare & 2 \\
\hline $\begin{array}{l}\text { Govaert GA et al } \\
\text { (12) }\end{array}$ & $\begin{array}{l}\text { Lymphatic map- } \\
\text { ping in breast } \\
\text { cancer }\end{array}$ & Blue staining & 33 \\
\hline Stradling B et al (5) & $\begin{array}{l}\text { Lymphatic map- } \\
\text { ping in breast } \\
\text { cancer }\end{array}$ & Skin necrosis & 5 \\
\hline Salhab M et al (6) & $\begin{array}{l}\text { Lymphatic map- } \\
\text { ping in breast } \\
\text { cancer }\end{array}$ & $\begin{array}{l}\text { Skin and fat } \mathrm{Ne}- \\
\text { crosis }\end{array}$ & 1 \\
\hline $\begin{array}{l}\text { Singh- } \\
\text { Ranger G et al (14) }\end{array}$ & $\begin{array}{l}\text { Immediate re- } \\
\text { constructive } \\
\text { breast surgery }\end{array}$ & $\begin{array}{l}\text { Capsular con- } \\
\text { traction }\end{array}$ & 1 \\
\hline Varghese et al (1) & $\begin{array}{l}\text { Lymphatic map- } \\
\text { ping in breast } \\
\text { cancer }\end{array}$ & $\begin{array}{l}\text { Temporary Blue } \\
\text { staining }\end{array}$ & 329 \\
\hline Komenaka et al (13) & $\begin{array}{l}\text { Lymphatic map- } \\
\text { ping in breast } \\
\text { cancer }\end{array}$ & $\begin{array}{l}\text { Palpable mass at } \\
\text { site of injection }\end{array}$ & 10 \\
\hline
\end{tabular}

Varghese et al (1), described safely injecting MBD in the subdermal plane in the subareolar region with $97.6 \%$ identification rate. Their only reported complication was temporary tattooing from MBD, which was also seen on Goavert et al series (12). Mathelin et al (2) and Soni et al (3) both used MBD safely without adverse reactions in SLN mapping. Stradling et al (5) was the first to describe local skin reactions to MBD injection for SLN mapping, including skin necrosis in 5 of 24 patients. Zakaria et al (4) and Salhab et al (6) both reported skin and fat necrosis in a small percentage of patients who received MBD injections for SLN mapping. Komenaka et al (13) described a palpable mass at the site of injection of MBD. Nearly all of the masses resolved by one year, however, one resolved after 18 months. None of the aforementioned patients required surgical debridement. Singh-Ranger et al (14) did report a complication that required surgical revision. They reported capsular contraction associated with MBD, after immediate reconstruction using breast prosthesis. In their case they attributed local inflammatory reaction from the MBD as the main cause of the capsular contraction.

\section{Pathological Considerations}

One of our patients (Case 1) presented with a well-developed region of fat necrosis with cavity formation. Fat necrosis is an important diagnostic consideration as it may persist and can clinically mimic carcinoma. Early in its development, fat necrosis is composed of disrupted fat cells and hemorrhage with an influx of histiocytes, some becoming multinucleate as they ingest debris. After several weeks the affected area develops peripheral fibrosis, often with calcification and forming a tumor-like lesion which may clinically mimic carcinoma (15). Attachment to the skin, dimpling and retraction are often evident. Central cystic degeneration may also occur with resultant cavity formation. This type of fat necrosis differs from fat necrosis caused by electrocautery. Electrocautery has evident thermal effect around the edges and involved areas and does not cause such extensive destruction beyond the local tissue perimeter, with several centimeters of fat necrosis, as in the case of our patient.

We are aware of 1 report of MBD contamination with Mycobacteria chelonae that caused infections in patients who had undergone facelifts (11). To our knowledge, our case represents the initial report of contaminated MBD in breast surgery patients. This is of particular concern due to the impact that contaminated MBD had on the surgical and adjuvant management of breast cancer for our patients. 
Our 2 case reports confirm the findings of previous publications that complications of $\mathrm{MBD}$ are capable of causing tissue necrosis. Of note, both of our patients required extensive surgical debridements, revealing that MBD does indeed have side effects not considered in the previously published literature. In our Case Report \#2, the discovery of a complicating Mycobacterial infection led to delayed adjuvant treatment and had a significant impact on our choice for systemic treatment.

The site of injection of blue dyes is still controversial. Historically, Giuliano et al (16), described using blue dye as peritumoral injection with good results; peritumoral injection of blue dye is the most common approach to lymphatic mapping with vital blue dyes. Veronesi et al (17) injected blue dyes subdermally. Intradermal, periareolar or subareolar sites have also been described $(18,19)$. There are a limited number of studies indicating high success rates of identifying SLNs using subareolar injection of blue dye (20-22). Rodier et al (23), using both blue dye and radiolabelled isotope, found that using periareolar injection was equivalent to using peritumoral injection in identifying SLN. There are several studies supporting the different sites of injection for blue dye, but subareolar and dermal injections have been proven to cause more local side effects, like discoloration of the breast, that can last several months (24). In our case it caused more than just discoloration but led to substantial tissue loss due to necrosis.

Lymphazurin had long been held as the standard for sentinel lymph node mapping in breast cancer(25). However, MBD has demonstrated equivalent efficacy in lymphatic mapping compared to Lymphazurin $(3,26-28)$, is less expensive, more readily available and is not associated with the potentially deleterious side effects of severe allergic reaction, including anaphylaxis $(3,8,29)$ as has been reported with Lymphazurin. Raut et al reported an incidence of severe anaphylactoid reaction to lymphazurin of $1.1 \%$; preoperative prophylaxis reduced the severity, but not the overall incidence $(0.5 \%)$ of adverse reactions to Lymphazurin blue dye (30). Blue urticaria and facial edema were the reactions observed after preoperative prophylaxis in that study.

As described in the above cases and table, MBD is not without its own potential for complications. The risk for complications of MBD should be taken into consideration when selecting a blue dye for lymphatic mapping. Both MBD and Lymphazurin are vital blue dyes. Either may be used in combination with radioactive colloid and a gamma probe for sentinel lymph node mapping. According to the ASCO guidelines, the greatest proportion of successful mappings and the lowest false negative rates are associated with the use of blue dye and radiolabelled colloid used in conjunction (7). However, Golshan and colleagues (31) have recently published data to show that sentinel nodes can be successfully identified with MBD only. Additionally, they recommend the use of MBD over lymphazurin, due to the latter's known potentially deleterious side effects of severe allergic reaction, anaphylaxis or even death.

The dosing and concentration of MBD, in successful identification of SLN, has been described as 1 5 milliliters $(\mathrm{ml})$ of $1 \%$ methylene blue $(3,5,31)$ or $1.25 \mathrm{mg} / \mathrm{ml}(2,4)$. We recommend using dilute MBD based on our institutional experience with this medication. MBD may indeed become the most prevalent vital blue dye for these reasons and due to intermittent national shortages of Lymphazurin blue dye (3). The importance of understanding its proper usage and potential complications, therefore, cannot be understated.

\section{Conclusions}

The use of MBD in breast surgery patients is not without risk. In both of these patients, MBD was integral to complications requiring surgical debridements for local wound problems. In each patient's case, severe necrosis and infection were present. Awareness should be raised regarding MBD's potential to elicit tissue necrosis resulting in significant morbidity, cosmetically unsatisfactory results and even delayed cancer treatment.

\section{Conflict of Interest}

The authors have declared that no conflict of interest exists.

\section{References}

1. Varghese P, Abdel-Rahman AT, Akberali S, Mostafa A, Gattuso JM, Carpenter R. Methylene blue dye--a safe and effective alternative for sentinel lymph node localization. Breast J. 2008;14(1):61-7.

2. Mathelin C, Croce S, Brasse D, Gairard B, Gharbi M, Andriamisandratsoa N, et al. Methylene blue dye, an accurate dye for sentinel lymph node identification in early breast cancer. Anticancer Res. 2009 Oct;29(10):4119-25.

3. Soni M, Saha S, Korant A, Fritz P, Chakravarty B, Sirop S, et al. A prospective trial comparing $1 \%$ lymphazurin vs $1 \%$ methylene blue in sentinel lymph node mapping of gastrointestinal tumors. Ann Surg Oncol. 2009 Aug;16(8):2224-30.

4. Zakaria S, Hoskin TL, Degnim AC. Safety and technical success of methylene blue dye for lymphatic mapping in breast cancer. Am J Surg. 2008 Aug;196(2):228-33.

5. Stradling B, Aranha G, Gabram S. Adverse skin lesions after methylene blue injections for sentinel lymph node localization. Am J Surg. 2002 Oct;184(4):350-2. 
6. Salhab M, Al Sarakbi W, Mokbel K. Skin and fat necrosis of the breast following methylene blue dye injection for sentinel node biopsy in a patient with breast cancer. Int Semin Surg Oncol. 2005 Nov 28;2:26.

7. Lyman GH, Giuliano AE, Somerfield MR, Benson AB3rd, Bodurka DC, Burstein HJ, et al. American Society of Clinical Oncology guideline recommendations for sentinel lymph node biopsy in early-stage breast cancer. J Clin Oncol. 2005;23(30):7703-20.

8. Thevarajah S, Huston TL, Simmons RM. A comparison of the adverse reactions associated with isosulfan blue versus methylene blue dye in sentinel lymph node biopsy for breast cancer. Am J Surg. 2005 Feb;189(2):236-9.

9. Stoeckel WT, David L, Levine EA, Argenta AE, Perrier ND. Vacuum-assisted closure for the treatment of complex breast wounds. Breast. 2006 Oct;15(5):610-3.

10. Leininger BE, Rasmussen TE, Smith DL, Jenkins DH, Coppola C. Experience with wound VAC and delayed primary closure of contaminated soft tissue injuries in Iraq. J Trauma. 2006 Nov;61(5):1207-11.

11. Centers for Disease Control and Prevention (CDC). Mycobacterium chelonae infections associated with face lifts--New Jersey, 2002-2003. MMWR Morb Mortal Wkly Rep. 2004;53(9):192-4.

12. Govaert GA, Oostenbroek RJ, Plaisier PW. Prolonged skin staining after intradermal use of patent blue in sentinel lymph node biopsy for breast cancer. Eur J Surg Oncol. 2005 May;31(4):373-5.

13. Komenaka GS, Bouton M. Prolonged Injection Site Mass Can Occur with Methylene Blue but Not Lymphazurin Blue After the Sentinel Node Procedure; Thirty-Second Annual CTRC-AACR San Antonio Breast Cancer Symposium; December 10-13, 2009. San Antonio, TX: American Association for Cancer Research. 2009.

14. Singh-Ranger G, Mokbel K. Capsular contraction following immediate reconstructive surgery for breast cancer - An association with methylene blue dye. Int Semin Surg Oncol. 2004 May 11;1(1):3.

15. Roisman I, Barak V, Manny J, Libson E, Wygoda M, Neuman A, et al. Fat necrosis below musculocutaneous flap mimicking carcinoma of breast. Ann Plast Surg. 1991 May;26(5):479-82.

16. Giuliano AE, Kirgan DM, Guenther JM, Morton DL. Lymphatic mapping and sentinel lymphadenectomy for breast cancer. Ann Surg. 1994;220(3):391-8.

17. Veronesi U, Paganelli G, Galimberti V, Viale G, Zurrida S, Bedoni $M$, et al. Sentinel-node biopsy to avoid axillary dissection in breast cancer with clinically negative lymph-nodes. Lancet. 1997;349(9069):1864-7.

18. Rubio IT, Klimberg VS. Techniques of sentinel lymph node biopsy. Semin Surg Oncol. 2001;20(3):214-23.

19. Layeeque R, Henry-Tillman R, Korourian S, Kass R, Klimberg VS. Subareolar sentinel node biopsy for multiple breast cancers. Am J Surg. 2003;186(6):730-5.

20. Kern KA. Sentinel lymph node mapping in breast cancer using subareolar injection of blue dye. J Am Coll Surg. 1999;189(6):539-45.

21. Kern KA. Concordance and validation study of sentinel lymph node biopsy for breast cancer using subareolar injection of blue dye and technetium 99m sulfur colloid. J Am Coll Surg. 2002;195(4):467-75.

22. Klimberg VS, Rubio IT, Henry R, Cowan C, Colvert M, Korourian S. Subareolar versus peritumoral injection for location of the sentinel lymph node. Ann Surg. 1999;229(6):860-4.

23. Rodier JF, Velten M, Wilt M, Martel P, Ferron G, Vaini-Elies V, et al. Prospective multicentric randomized study comparing periareolar and peritumoral injection of radiotracer and blue dye for the detection of sentinel lymph node in breast sparing procedures: FRANSENODE trial. J Clin Oncol. 2007 Aug 20;25(24):3664-9.

24. Samphao S, Eremin JM, El-Sheemy M, Eremin O. Management of the axilla in women with breast cancer: current clinical practice and a new selective targeted approach. Ann Surg Oncol. 2008 May;15(5):1282-96.

25. Newman EA, Newman LA. Lymphatic mapping techniques and sentinel lymph node biopsy in breast cancer. Surg Clin North Am. 2007;87(2):353-64

26. Blessing WD, Stolier AJ, Teng SC, Bolton JS, Fuhrman GM. A comparison of methylene blue and lymphazurin in breast cancer sentinel node mapping. Am J Surg. 2002 Oct;184(4):341-5.

27. Liu Y, Truini C, Ariyan S. A randomized study comparing the effectiveness of methylene blue dye with lymphazurin blue dye in sentinel lymph node biopsy for the treatment of cutaneous melanoma. Ann Surg Oncol. 2008 Sep;15(9):2412-7.

28. Simmons R, Thevarajah S, Brennan MB, Christos P, Osborne M. Methylene blue dye as an alternative to isosulfan blue dye for sentinel lymph node localization. Ann Surg Oncol. 2003 Apr;10(3):242-7.

29. Sandhu S, Farag E, Argalious M. Anaphylaxis to isosulfan blue dye during sentinel lymph node biopsy. J Clin Anesth. 2005 Dec;17(8):633-5.

30. Raut CP, Hunt KK, Akins JS, Daley MD, Ross MI, Singletary SE, et al. Incidence of anaphylactoid reactions to isosulfan blue dye during breast carcinoma lymphatic mapping in patients treated with preoperative prophylaxis: results of a surgical prospective clinical practice protocol. Cancer. 2005 Aug 15;104(4):692-9.

31. Golshan M, Nakhlis F. Can methylene blue only be used in sentinel lymph node biopsy for breast cancer? Breast J. 2006;12(5):428-30. 